Kalpa Publications in Computing
Volume 2, 2017, Pages 119-129
ICRISET2017. International Conference on Re-
search and Innovations in Science, Engineer-
ing \&Technology. Selected Papers in Computing

\title{
Ferrofluid based squeeze film for a rough conical bearing with deformation effect
}

\author{
Jimit R. Patel ${ }^{1 *}$, M. E. Shimpi ${ }^{2}$ and G. M. Deheri ${ }^{3}$ \\ ${ }^{1}$ Department of Applied Science, \\ Parul Institute of Technology, Faculty of Engineering and Technology, Parul University, Limda, \\ Vadodara-391760, India. \\ ${ }^{2}$ Department of Mathematics, \\ Birla Vishvakarma Mahavidyalaya Engineering College, Vallabh Vidyanagar-388120, Gujarat \\ State, India. \\ ${ }^{3}$ Department of Mathematics, \\ Sardar Patel University, Vallabh vidyanagar-388120, Gujarat State, India. \\ patel.jimitphdmarch2013@gmail.com, mukesh.shimpi@gmail.com, \\ $\mathrm{gm}$.deherierediffmail.com.
}

\begin{abstract}
This paper aims to discuss the combined effect of longitudinal surface roughness and deformation on the behavior of a ferrofluid based squeeze film in conical plates. The Neuringer and Rosenweig model for ferrofluid flow has been considered resorting to an unusual form of the magnitude of the magnetic field. For the evaluation of surface roughness the stochastic model of Christensen and Tonder has been adopted. The concerned stochastically averaged Reynolds type equation is solved to obtain the pressure distribution which results in the calculation of load carrying capacity. The results establish that the positive effect of magnetization adds to the positive effect of longitudinal surface roughness under restricted circumstances. However, for an overall improved performance the bearing deformation must be addressed carefully as it has a significant effect on the squeeze film behavior. Besides, this article offers an additional degree of freedom through the magnitude of the magnetic field for designing the bearing system.
\end{abstract}

${ }^{*}$ Corresponding author 


\section{Introduction}

These magnetic fluids are a kind of multi functional materials which are manufactured by dispersing the magnetic particles into a carrying liquid. (Jacod et al, 2004) dealt with the effect of longitudinal roughness on the friction in EHL contacts by means of numerical simulations. It was shown that for the effect on friction such a combined pattern could be represented by a single equivalent wave. The performance of a squeeze film formed by a magnetic fluid between longitudinally rough conical plates analyzed in (Andharia and Deheri, 2010). By choosing a suitable combination of the magnetization parameter and the semi-vertical angle of the cone, the performance of the longitudinally rough bearing system could be enhance. (Vadher et al, 2011) deliberated on the behavior of a hydromagnetic squeeze film between conducting porous transversely rough truncated conical plates. It was examined that the negative effect induced by porosity and standard deviation could be overcome completely by the positive effect of the magnetization parameter and conductivities by choosing suitable aspect ratio and the semi-vertical angle in the case of negatively skewed roughness. The behaviour of a magnetic fluid based squeeze film between rough porous truncated conical plates by taking into consideration the effects of bearing deformation and slip velocity discussed in (Shimpi and Deheri, 2014). It was found that the combined effect of bearing deformation and slip velocity was relatively adverse. The magnetic fluid lubricant saved the situation to a limited extent, at least in the case of the negatively skewed roughness. (Shah and Parikh, 2014) studied the effects of ferrofluid lubricant on slider bearings considering rotation of the magnetic particles and their magnetic moments under a constant transverse magnetic field. It was noted that a constant magnetic field did not enhance load carrying capacity in Rosensweig's ferrofluid flow model whereas it did in the case of the Shliomis model. (Lin, 2016) analyzed the performance characteristics of a magnetic fluid lubricated short journal bearing with rough surfaces using the magnetic fluid model incorporating the stochastic model. It was obtained that the effects of longitudinal roughness patterns result in an increased load capacity as well as a reduced friction parameter and attitude angle. (Patel and Deheri, 2016) presented a comparison of all the three magnetic fluid flow models so far as the performance of a magnetic fluid based parallel plate rough slider bearing. It was found that for a bearing's long life period the Shliomis model might be employed for higher loads.

\section{Analysis}

The geometry of the bearing system, which is infinite in the Y- direction is displayed in Figure 1.

Here, $\dot{h}=\frac{d h}{d t}$ is the squeeze film velocity in the z-direction. The magnetic field $M$ is oblique to the lower plate. 
Ferrofluid based squeeze film for a rough conical bearing... Jimit Patel, M. E. Shimpi, G. M. Deheri

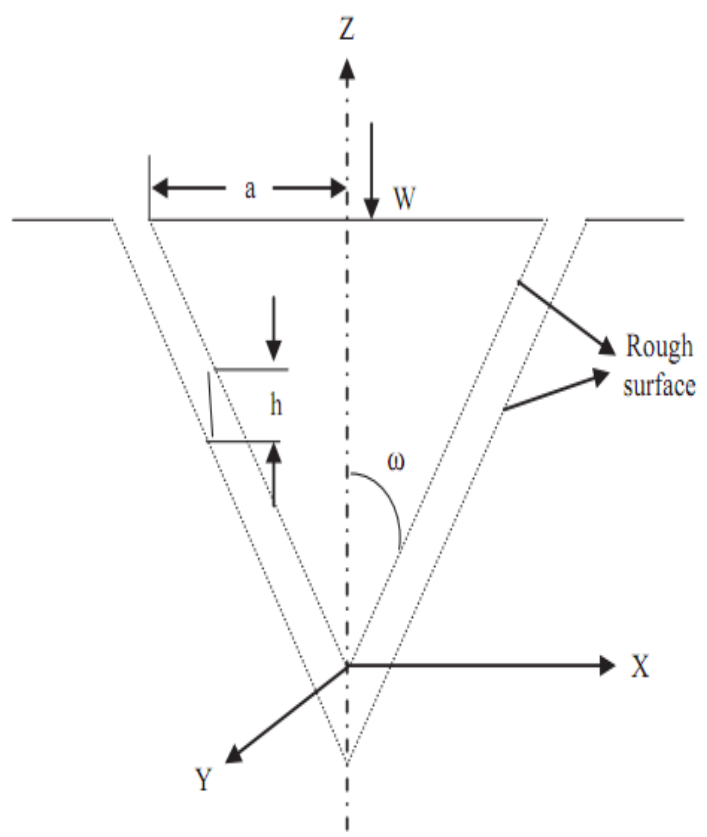

Figure 1: Configuration of the bearing system.

In view of usual assumptions of the hydromagnetic lubrication, the related Reynold's equation ((Andharia and Deheri, 2010), (Shimpi and Deheri, 2014), Patel and Deheri, 2016)) governing the in the present study is obtained as,

$$
\frac{1}{x} \frac{d}{d x}\left[x h^{3} \frac{d}{d x}\left(p-\frac{1}{2} \mu_{0} \bar{\mu} M^{2}\right)\right]=\frac{12 \mu \dot{h}_{0}}{\sin ^{2} \omega}
$$

Where

$$
M^{2}=\frac{x^{2}}{a^{2}} \sin ^{2} \omega \sin \left(1-\frac{x^{2}}{a^{2}} \sin ^{2} \omega\right)
$$

Here longitudinally rough bearing surfaces are considered. Therefore, the stochastic film thickness of the lubricant film, according to discussions of Christensen and Tonder ((Andharia and Deheri, 2010), (Shimpi and Deheri, 2014), Patel and Deheri, 2016)), is assumed as to be

$$
h=\bar{h}+h_{\mathrm{s}}
$$

Where $h_{s}$ is hypothetical to be stochastic in nature and governed by the probability density function

$$
f\left(h_{s}\right)=\left\{\begin{array}{c}
\frac{35}{32 c}\left(\begin{array}{c}
1-\frac{h_{s}^{2}}{c^{2}} \\
0, \text { elsewhere }
\end{array}\right)^{3},-c \leq h_{s} \leq c \\
\text { olsew }
\end{array}\right.
$$

Following the theory of averaging process discussed in (Andharia and Deheri, 2010), equation (1) turns out to be of the form:

$$
\frac{1}{x} \frac{d}{d x}\left[x m(\bar{h})^{-1} \frac{d}{d x}\left(p-\frac{1}{2} \mu_{0} \bar{\mu} M^{2}\right)\right]=\frac{12 \mu \dot{h}_{0}}{\sin ^{2} \omega}
$$


Ferrofluid based squeeze film for a rough conical bearing... Jimit Patel, M. E. Shimpi, G. M. Deheri

Where $p$ is the expected value of the lubricant pressure while

$$
\begin{gathered}
m(\bar{h})=\left(h+p_{a} p^{\prime} \delta\right)^{-3}\left[1-3\left(h+p_{a} p^{\prime} \delta\right)^{-1} \alpha+\sigma\left(h+p_{a} p^{\prime} \delta\right)^{-2}\left(\sigma^{2}+\alpha^{2}\right)\right. \\
\left.-20\left(h+p_{a} p^{\prime} \delta\right)^{-3}\left(3 \sigma^{2} \alpha+\alpha^{3}+\varepsilon\right)\right]
\end{gathered}
$$

The associated boundary conditions are,

$$
p(\operatorname{acosec} \omega)=0,\left(\frac{d p}{d x}\right)_{x=0}=0
$$

Using these boundary conditions, equation (2) takes the form,

$$
\frac{d}{d x}\left(p-\frac{1}{2} \mu_{0} \bar{\mu} M^{2}\right)=\frac{6 \mu \dot{h}_{0}}{\sin ^{2} \omega} x m(\bar{h})
$$

Introducing the non dimensional quantities,

Wherein

$$
\begin{gathered}
H=\frac{h}{h_{0}}, X=\frac{X}{\operatorname{acosec} \omega}, K(H)=h_{0}^{3} m(\bar{h}), \bar{\sigma}=\frac{\sigma}{h_{0}}, \\
\bar{\alpha}=\frac{\alpha}{h_{0}}, \bar{\varepsilon}=\frac{\varepsilon}{h_{0}^{3}}, P=-\frac{h_{0}^{3} p}{\mu \dot{h}_{0} A}, \mu^{*}=-\frac{\mu_{0} \bar{\mu} h_{0}^{3}}{\mu \dot{h}_{0}}, \\
\bar{p}=p_{a} p^{\prime}, \bar{\delta}=\frac{\delta}{h}
\end{gathered}
$$

$$
A=\frac{a^{2} \pi}{\sin \omega}
$$

The $P$ under the boundary condition $P=0$ at $X=1$ can be found to be,

where

$$
P=\frac{\mu^{*} X^{2} \sin \left(1-X^{2}\right) \sin \omega}{\pi}+\frac{3 K(H)}{\pi \sin ^{3} \omega}\left(1-X^{2}\right)
$$

$$
\begin{gathered}
K(H)=H^{-3}(1+\bar{p} \bar{\delta})^{-3}\left[1-3 H^{-1}(1+\bar{p} \bar{\delta})^{-1}+\overline{6 H^{-2}(1+\bar{p} \bar{\delta})^{-2}\left(\bar{\sigma}^{2}+\bar{\alpha}^{2}\right) \alpha}\right. \\
\left.-20 H^{-3}(1+\bar{p} \bar{\delta})^{-3}\left(3 \bar{\sigma}^{2} \bar{\alpha}+\bar{\alpha}^{3}+\bar{\varepsilon}\right)\right]
\end{gathered}
$$

The dimensionless $W$ is obtained as,

$$
\begin{gathered}
W=-\frac{w h_{0}^{3}}{\mu \dot{h}_{0} A^{2}}=\int_{0}^{l} P d X \\
=\frac{\mu^{*} \sin \omega}{\pi} \int_{0}^{1} X^{2} \sin \left(1-X^{2}\right) d x+\frac{2 K(H)}{\pi \sin ^{3} \omega} \\
=\frac{\mu^{*} \sin \omega}{\pi}(0.125101)+\frac{2 K(H)}{\pi \sin ^{3} \omega}
\end{gathered}
$$

where 
Ferrofluid based squeeze film for a rough conical bearing... Jimit Patel, M. E. Shimpi, G. M. Deheri

$$
w=2 \pi \int_{0}^{\operatorname{acosec} \omega} x p(x) d x
$$

\section{Results And Discussion}

To It can be noticed that the expression involved in the equation (7) is linear with respect $\mu^{*}$ and hence an increase in $\mu^{*}$ would lead to increase load carrying capacity. In the absence of deformation this study reduces to the investigation of (Andharia and Deheri, 2010).

The effect of $\bar{\delta}$ given in Figures 2-6 tells that there occurs a considerable load decrease due to the bearing deformation. However, the effect of roughness parameters on the load carrying capacity with respect to deformation remains negligible.

The fact that $\bar{\sigma}$ increases the load carrying capacity nominally, is depicted in Figures 7-8. Further the combined effect of $\bar{\sigma}$ and negatively skewed roughness turns to significantly positive [Figure 8 ], as the load rises sharply.

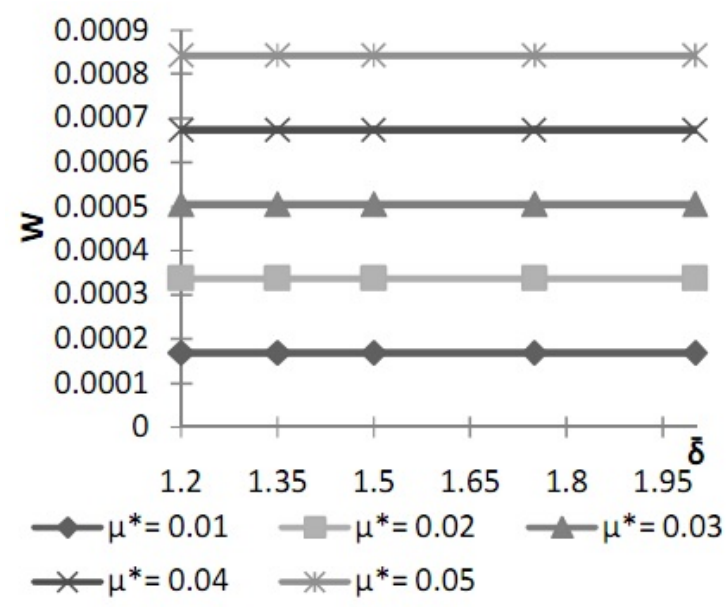

Figure 2: Variation of $W$ with respect to $\bar{\delta}$ and $\mu^{*}$. 
Ferrofluid based squeeze film for a rough conical bearing... Jimit Patel, M. E. Shimpi, G. M. Deheri

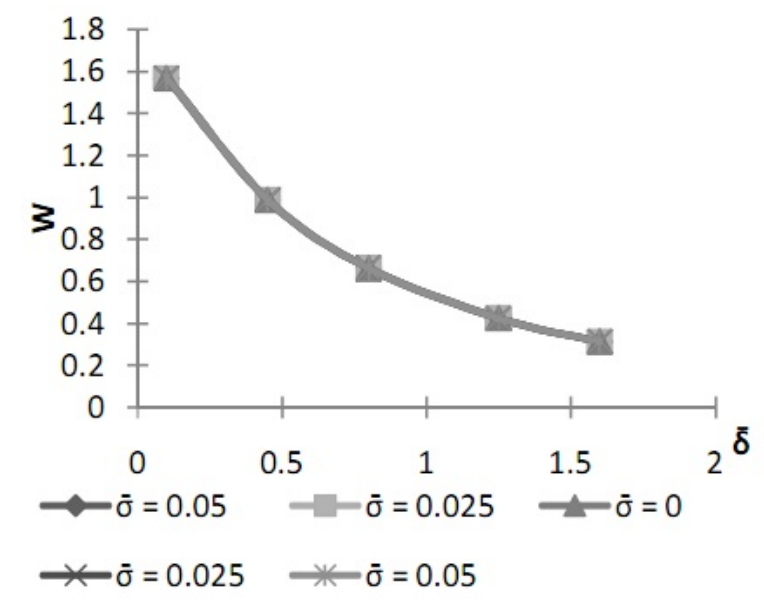

Figure 3: Variation of $W$ with respect to $\bar{\delta}$ and $\bar{\sigma}$.

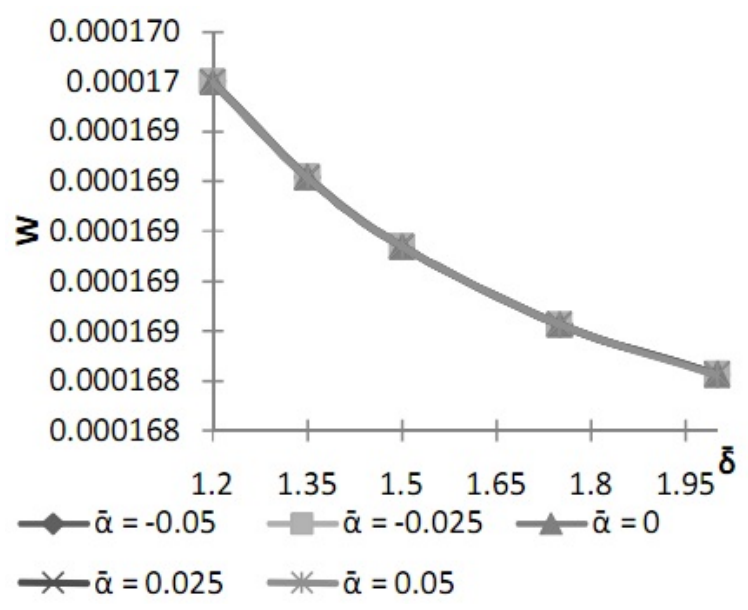

Figure 4: Variation of $W$ with respect to $\bar{\delta}$ and $\bar{\alpha}$.

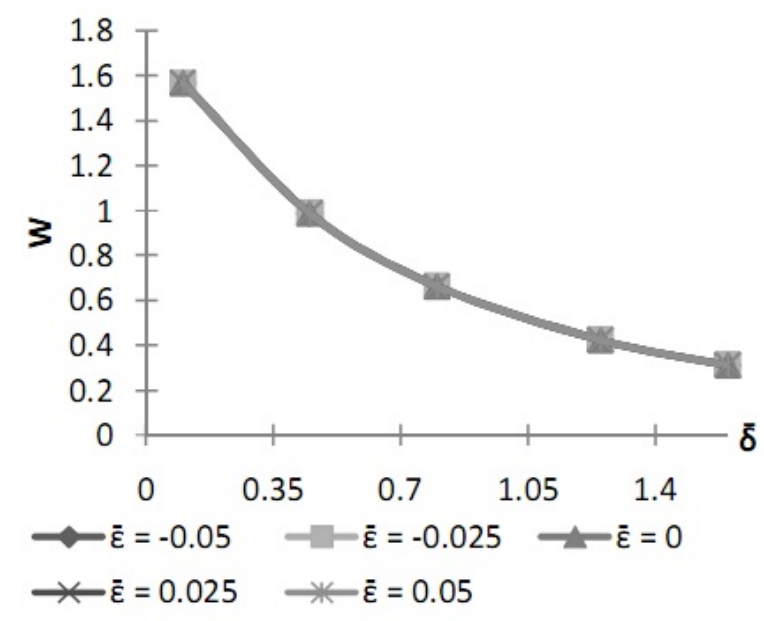


Ferrofluid based squeeze film for a rough conical bearing... Jimit Patel, M. E. Shimpi, G. M. Deheri

Figure 5: Variation of $W$ with respect to $\bar{\delta}$ and $\bar{\varepsilon}$.

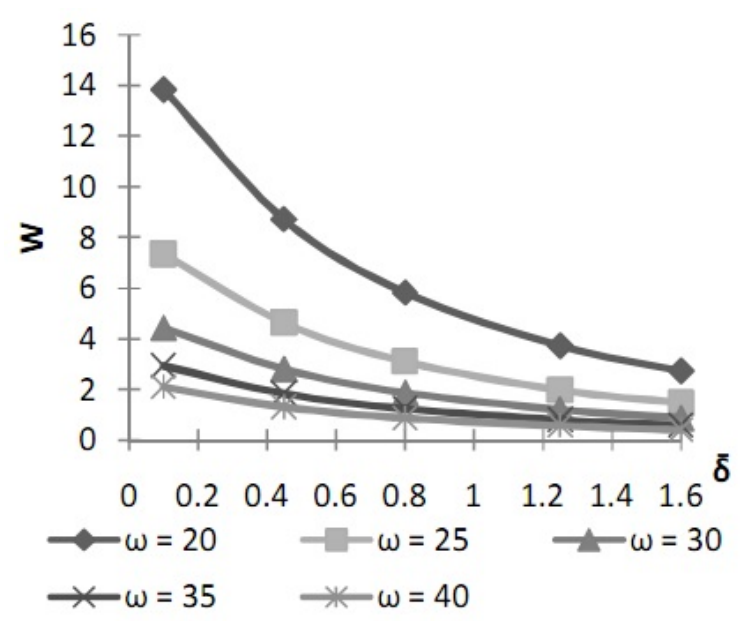

Figure 6: Variation of $W$ with respect to $\bar{\delta}$ and $\omega$.

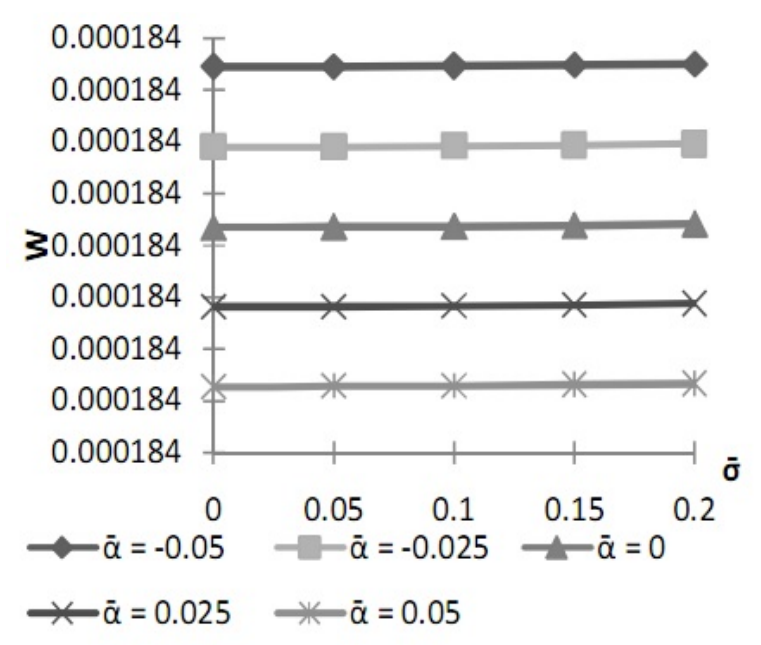

Figure 7: Variation of $W$ with respect to $\bar{\sigma}$ and $\bar{\alpha}$. 
Ferrofluid based squeeze film for a rough conical bearing... Jimit Patel, M. E. Shimpi, G. M. Deheri

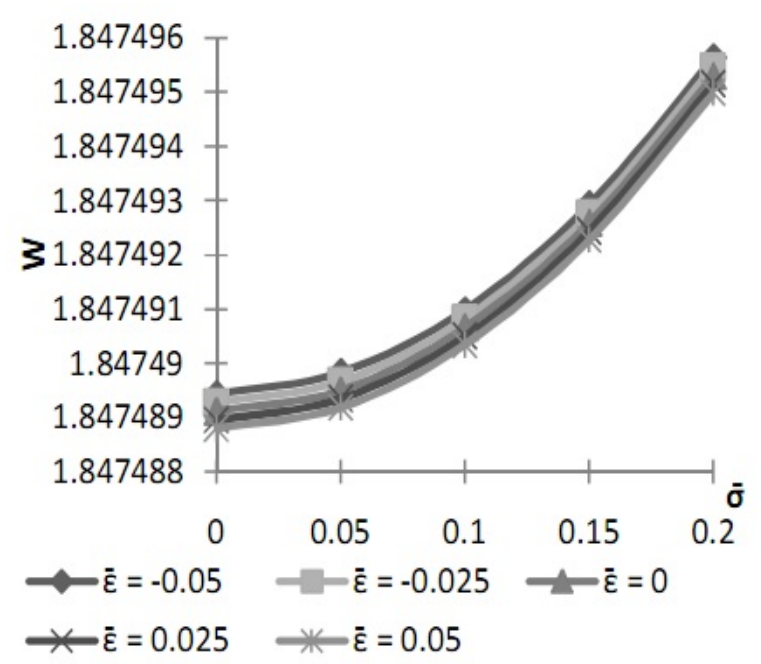

Figure 8: Variation of $W$ with respect to $\bar{\sigma}$ and $\bar{\varepsilon}$.

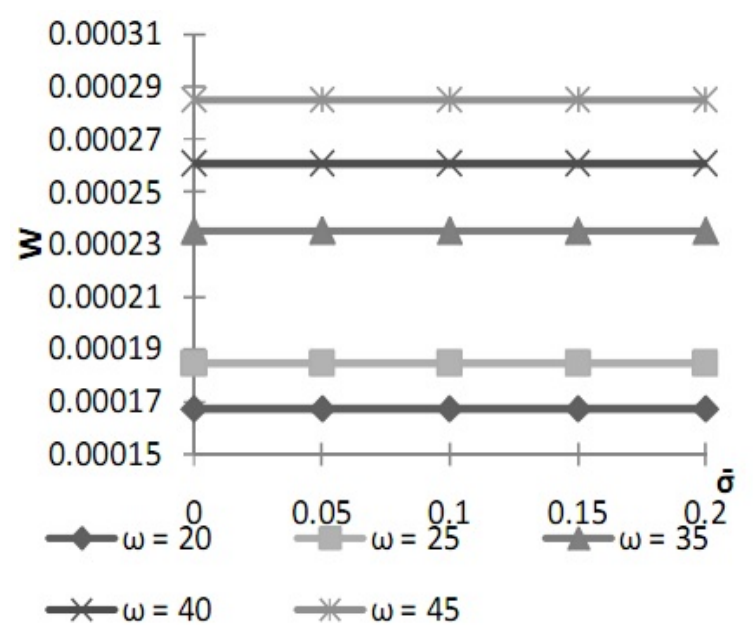

Figure 9: Variation of $W$ with respect to $\bar{\sigma}$ and $\omega$. 
Ferrofluid based squeeze film for a rough conical bearing... Jimit Patel, M. E. Shimpi, G. M. Deheri

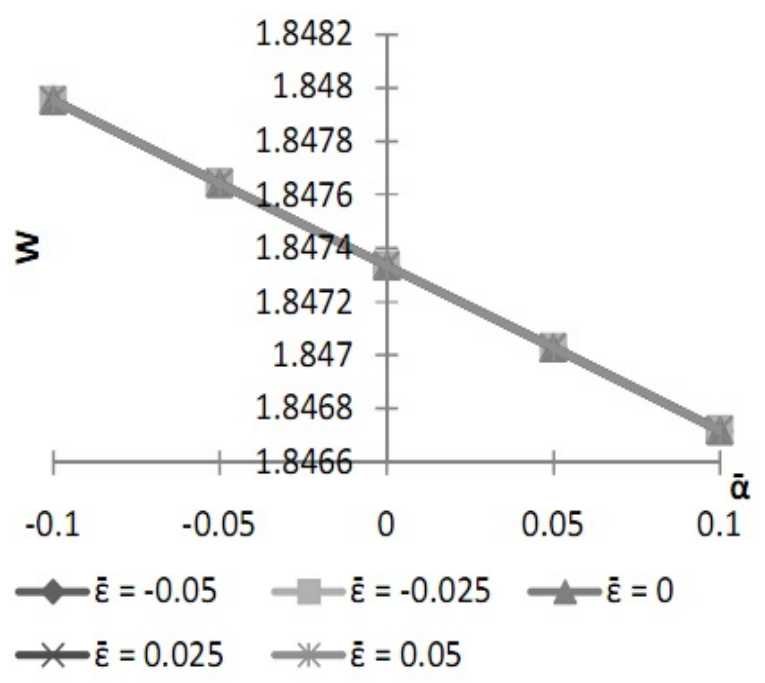

Figure 10: Variation of $W$ with respect to $\bar{\alpha}$ and $\bar{\varepsilon}$.

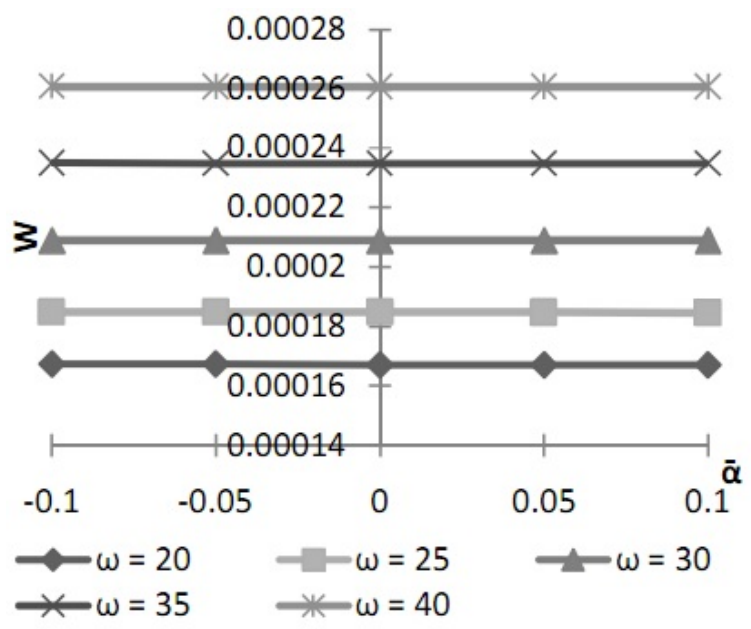

Figure 21: Variation of $W$ with respect to $\bar{\alpha}$ and $\omega$.

It is appealing to note that the effect of skewness on load carrying capacity with respect to variance is negligible which rarely happens. This is a study in contrast as can be seen from (Shimpi and Deheri, 2014) and (Patel and Deheri, 2016).

The variance effect is marginal [Figures 9] however, load carrying capacity decreases with variance $(+v e)$ while load is observed to be more in the case of variance (-ve). 
Ferrofluid based squeeze film for a rough conical bearing... Jimit Patel, M. E. Shimpi, G. M. Deheri

\section{Conclusion}

It is found that in most of the situations the effect of surface roughness and deformation is relatively adverse, this investigation proves that magnetism has a sobering effect especially, when negatively skewed roughness is involved and variance (-ve) occurs. But, this positive effect of magnetization may not go a long way in mitigating the negative effect of roughness. Therefore, the roughness aspects need to be addressed for a good bearing design.

\section{Nomenclature}

\begin{tabular}{|c|c|c|c|c|c|}
\hline Symbol & Name & Symbol & Name & Symbol & Name \\
\hline$p$ & $\begin{array}{l}\text { Lubricant } \\
\text { pressure }\end{array}$ & $\mu_{0}$ & $\begin{array}{l}\text { The permeability } \\
\text { of free space }\end{array}$ & $\varepsilon$ & Skewness \\
\hline$w$ & $\begin{array}{l}\text { Load carrying } \\
\text { capacity }\end{array}$ & $P$ & $\begin{array}{l}\text { Dimensionless } \\
\text { pressure }\end{array}$ & $\mu$ & $\begin{array}{l}\text { Viscosity of } \\
\text { lubricant }\end{array}$ \\
\hline$\alpha$ & Variance & $W$ & $\begin{array}{l}\text { Dimensionless } \\
\text { load carrying } \\
\text { capacity }\end{array}$ & $\delta$ & Deformation \\
\hline$\sigma$ & $\begin{array}{l}\text { Standard } \\
\text { deviation }\end{array}$ & $\bar{\alpha}$ & $\begin{array}{l}\text { Variance in non- } \\
\text { dimensional form }\end{array}$ & $p_{a}$ & $\begin{array}{l}\text { The reference } \\
\text { ambient pressure }\end{array}$ \\
\hline $\bar{\sigma}$ & $\begin{array}{l}\text { Dimensionless } \\
\text { standard } \\
\text { deviation }\end{array}$ & $\bar{\varepsilon}$ & $\begin{array}{l}\text { Non-dimensional } \\
\text { skewness }\end{array}$ & $\mu^{*}$ & $\begin{array}{l}\text { Dimensionless } \\
\text { magnetization } \\
\text { parameter }\end{array}$ \\
\hline $\bar{\delta}$ & $\begin{array}{l}\text { Dimensionless } \\
\text { deformation }\end{array}$ & a & $\begin{array}{l}\text { Dimension of the } \\
\text { bearing }\end{array}$ & $\omega$ & $\begin{array}{l}\text { Semi-vertical } \\
\text { angle of cone }\end{array}$ \\
\hline$h$ & film thickness & $\bar{\mu}$ & $\begin{array}{l}\text { The magnetic } \\
\text { susceptibility }\end{array}$ & $\bar{h}$ & $\begin{array}{l}\text { The mean film } \\
\text { thickness }\end{array}$ \\
\hline$h_{s}$ & $\begin{array}{l}\text { The deviation } \\
\text { from the mean } \\
\text { film thickness }\end{array}$ & c & $\begin{array}{l}\text { The maximum } \\
\text { deviation from } \\
\text { the mean film } \\
\text { thickness }\end{array}$ & & \\
\hline
\end{tabular}

\section{ACKNOWLEDGMENT}

The authors acknowledge with thanks the fruitful comments and constructive suggestions of the reviewers.

\section{References}

Jacod B., Venner C.H. and Lugt P.M. (2004). Influence of Longitudinal Roughness on Friction in EHL Contacts, Journal of Tribology (vol. 126, pp. 473-481).

Andharia P. I. and Deheri G (2010). Longitudinal roughness effect on magnetic fluid based squeeze film between conical plates, Industrial Lubrication and Tribology (vol. 62(5), pp. 285-291). 
Ferrofluid based squeeze film for a rough conical bearing... Jimit Patel, M. E. Shimpi, G. M. Deheri

Vadher P. A., Deheri G. M. and Patel, R. M. (2011). Effect of transverse surface roughness on the performance of hydromagnetic squeeze film between conducting truncated conical plates, Journal of Marine Science and Technology(Vol. 19, No. 6, pp. 673-680).

Shimpi M. E. and Deheri G. M.(2014). Effect of slip velocity and bearing deformation on the performance of a magnetic fluid based rough porous truncated conical plates, IJST, Transactions of Mechanical Engineering(vol. 38, No. M1+, pp. 195-206).

Shah R. C. and Parikh K. S. (2014) Comparative study of ferrofluid lubricated various designed slider bearings considering rotation of magnetic particles and squeeze velocity, International Journal of Theoretical and Mathematical Physics (vol. 4, pp. 63-72).

Lin J. R. (2016). Longitudinal Surface Roughness Effects In Magnetic Fluid Lubricated Journal Bearings, Journal of Marine Science and Technology (vol. 24, No. 4, pp. 711-716).

Patel, J.R. and Deheri, G.M. (2016). Performance of a Ferrofluid Based Rough Parallel Plate Slider Bearing: A Comparison of Three Magnetic Fluid Flow Models, Advances in Tribology( Vol. 2016, Article ID 8197160). 